\title{
Current condition of genetic medicine for hereditary breast cancer
}

\author{
HIROKO TERUI-KOHBATA $^{1,2}$ and MASAYUKI YOSHIDA ${ }^{1,2}$ \\ ${ }^{1}$ Bioethics Research Center, Tokyo Medical and Dental University; ${ }^{2}$ Division of Medical Genetics, \\ Medical Hospital of Tokyo Medical and Dental University, Tokyo 113-8510, Japan
}

Received September 21, 2016; Accepted March 17, 2017

DOI: $10.3892 /$ mco.2017.1260

\begin{abstract}
BRCA1 or BRCA2 (BRCA1/2) germline mutations, which cause hereditary breast and ovarian cancer syndrome, have been studied to develop targeted therapies for these associated cancer types. The BRCA1/2 test has been implemented in more than one hundred medical facilities in a clinical setting in Japan. The purpose of the current study is to document the prevalence and the awareness of genetic medicine for all hereditary breast cancer (HBC) including the BRCA1/2 test in Japan. The self-administered questionnaire was sent to 120 medical facilities where the BRCA1/2 test was provided, and 83 health care professionals participated (response rate, $69.2 \%)$. Of the all respondents, $33.7 \%(\mathrm{~N}=42)$ were clinical geneticists, $31.3 \%(\mathrm{~N}=26)$ other physicians, $15.7 \%(\mathrm{~N}=13)$ genetic counselors and $2.4 \%(\mathrm{~N}=2)$ nurses. In the most recent one-year period, in $83.1 \%$ of the 69 facilities the number of patients who underwent genetic testing for HBC was $<10$ and only 4 facilities provided multigene panel testing for HBC. In order to facilitate the access to genetic medicine, the majority of the genetic counselors $(58.3 \%)$ recognized the need for education of healthcare professionals. Although the awareness of and interests in HBC have increased gradually, the equitable access to precision medicine is considered to be a challenging issue in Japan.
\end{abstract}

\section{Introduction}

The number of individuals affected with breast cancer has increased globally. In Japan, 89,400 females were newly diagnosed with breast cancer and there were 13,800 mortalities attributed to this disease in 2015 (1). Approximately $20 \%$ of breast cancer patients have a family history and 5-10\% $(2,3)$

Correspondence to: Dr Masayuki Yoshida, Bioethics Research Center, Tokyo Medical and Dental University, 1-5-45 Yushima, Bunkyo-ku, Tokyo 113-8510, Japan

E-mail: masa.vasc@tmd.ac.jp

Abbreviations: BRCA1 or BRCA2 gene, BRCA1/2; HBC, hereditary breast cancer; HBOC, hereditary breast and ovarian cancer syndrome

Key words: genetic medicine, HBOC, BRCA1/2 genetic testing, hereditary breast cancer, genetic counseling are considered to be hereditary (hereditary breast cancer) HBC caused by a germline mutation such as BRCA1, BRCA2, TP53 or PTEN. Mutations in BRCA1/2 genes are associated with hereditary breast and ovarian cancer syndrome (HBOC), which is the most common form of HBC. It is also known that germline mutations of DNA mismatch repair (MMR) genes, such as MLH1, MSH2 and MSH6 are caused by Lynch syndrome, which is a hereditary colorectal cancer syndrome, and $M L H 1$ particularly increases the risk of breast cancer (4).

Women with HBOC have a 41-90\% lifetime risk of developing breast cancer (5) and HBOC is characterized by the high risk of contralateral breast cancer (6). In addition, the cumulative risk for ovarian cancer is $8-59 \%$ and is higher in BRCA1 mutation carriers compared with BRCA2 mutation carriers (5-7). It was revealed that triple-negative breast cancer, which is estrogen receptor/progesterone receptor-negative and human epidermal growth factor receptor 2, negative was associated with $\mathrm{HBOC}$ and that $36 \%$ of women with early-onset triple-negative breast cancer (aged $<40$ years) had a BRCA1 mutation and $27 \%$ of women with triple-negative breast cancer diagnosed before the age of 50 years had a $B R C A 1$ mutation (8). Male BRCA1/2 mutation carriers are also at increased risk of cancer. The cumulative risk of breast cancer is $1.2 \%$ in male $B R C A 1$ mutation carriers and $6.8 \%$ in male $B R C A 2$ mutation carriers (9), and the risk of prostate cancer of $B R C A 2$ mutation carriers is increased to $\sim 3$ times higher than that of the general population $(10,11)$. Owing to the early onset and susceptibility of multiple cancer associated with HBOC, the importance of surveillance from a younger age has been emphasized (12). For female carriers of a BRCA1/2 mutation, a monthly breast self-examination from the age of 18 , an annual breast MRI or mammography between the ages of 25 and 29 and an annual breast MRI and mammography over 30 years of age are recommended. However, the usefulness of surveillance programs for cancer risks is not clear, and an appropriate screening method has not been established. Therefore, once a BRCA1/2 mutation is identified in cancer patients and their families, the option of the risk reducing mastectomy (RRM) and the risk reducing bilateral salpingo-oophorectomy (RRSO) must be considered. In the retrospective study, the 20 -year survival rate for females with a $B R C A 1 / 2$ mutation who underwent contralateral prophylactic mastectomy was $88 \%$ and for those who did not was $66 \%$ (13). Also, the results of meta-analysis revealed that RRSO reduced ovarian cancer risk by $80 \%$ and breast cancer risk by $50 \%$ in female $B R C A 1 / 2$ 
mutation carriers (14). Furthermore, in a short-term follow-up study, RRSO reduced breast cancer-specific mortality by $90 \%$, and gynecologic cancer-specific mortality by $95 \%$ and overall mortality by $76 \%$ (15). In addition, the use of the oral poly ADP-ribose polymerase inhibitor Lynparza ${ }^{\mathrm{TM}}$ (olaparib) for patients with advanced ovarian cancer with a BRCA1/2 mutation was approved by the FDA in December 2014. Although the clinical trial for this drug has not yet been completed in Japan (16), it may become a promising new drug for patients with $B R C A 1 / 2$-associated cancer once approved.

The frequency of variants of uncertain significance (VUS) on the $B R C A 1 / 2$ gene was $2-6 \%$ in the Caucasian population in the US $(17,18)$ and this frequency is thought to be greater in other countries with varying ethnic backgrounds due to the small number of patients undergoing BRCA1/2 testing. Therefore proper assessment of VUS has become a major issue in clinical genetic testing. Furthermore, previous studies have demonstrated that BRCA1/2 mutation-negative patients harbored deleterious mutations in moderate-risk cancer genes such as CHEK2, ATM, and PALB2 and MMR $(19,20)$ Despite an increasing number of $\mathrm{HBC}$ testing facilities, there is little information available regarding attitudes towards precision medicine for HBC in Japan.

\section{Patients and methods}

Study subjects and questionnaire. A total of 120 medical facilities were selected for this survey because those facilities may be confirmed on the website to be providing the BRCAl/2 tests for patients with cancer and their families. The written information on this survey and self-administered questionnaire were sent to the facilities between September and October 2015. The questionnaire contained the following items: i) the outline of the respondents' facilities, ii) the respondents' characteristics such as their affiliation and specialty, iii) the number of clients who visited for genetic counseling and/or received genetic testing for $\mathrm{HBC}$ in the most recent one-year period, iv) the current status of implementation of RRM and RRSO and v) the requirements for improving access to genetic counseling. The subjects filled in the questionnaire if they consented to participate in the study. The collected data were calculated as totals, means, medians or percentages and the free descriptive answers were categorized. The study protocol was approved by the Medical Research Ethics Committee of Tokyo Medical and Dental University (Tokyo, Japan) (no. 2231).

\section{Results}

Background information of the facilities and the health care professionals. The questionnaire was sent to 120 medical facilities, and a total of 83 health care professionals participated (response rate, 69.2\%). Approximately one half of the respondents belonged to university hospitals ( $\mathrm{N}=40,48.2 \%)$ and to the division of medical genetics $(\mathrm{N}=37,44.6 \%)$, and the majority were genetics professionals ( $\mathrm{N}=55,67.3 \%)$, such as clinical geneticists and genetic counselors (Table I).

The number of clients who underwent genetic testing. In $66.3 \%(\mathrm{~N}=55)$ of the respondent's facilities, the number of
Table I. The outline of the facilities and the respondents' characteristics.

\begin{tabular}{lrc} 
A, Summary of facility & & \\
\hline & $\mathrm{N}$ & $\%$ \\
\hline Type & & \\
University hospital & 40 & 48.2 \\
Cancer center & 8 & 9.6 \\
Other hospital & 26 & 31.3 \\
Clinic & 8 & 9.6 \\
Other & 1 & 1.2 \\
Number of beds & & \\
$<50$ & 8 & 9.6 \\
$<100$ & 6 & 7.2 \\
$<200$ & 4 & 4.8 \\
$<500$ & 19 & 22.9 \\
$<1,000$ & 39 & 47.0 \\
$>1,000$ & 7 & 8.4 \\
\end{tabular}

B, Number of breast cancer surgeries/year

\begin{tabular}{lrc}
\hline & $\mathrm{N}$ & $\%$ \\
\hline non-performance & 8 & 9.6 \\
$<50$ & 13 & 15.7 \\
$<200$ & 36 & 43.4 \\
$<500$ & 24 & 29.0 \\
$>500$ & 2 & 2.4 \\
\hline
\end{tabular}

C, Respondent's characteristics

$\mathrm{N} \quad \%$

\begin{tabular}{lrc}
\hline Division & & \\
Medical genetics & 37 & 44.6 \\
Breast surgery & 28 & 33.7 \\
Obstetrics \& gynecology & 8 & 9.6 \\
Other & 10 & 12.0 \\
Specialty & & \\
Clinical geneticist & 42 & 50.6 \\
Other physician & 26 & 31.3 \\
Genetic counselor & 13 & 15.7 \\
Nurse & 2 & 2.4 \\
\end{tabular}

patients who visited genetic counseling regarding $\mathrm{HBC}$ in the most recent one-year period was $<10$ (Fig. 1). In total, $24.1 \%$ $(\mathrm{N}=20)$ of the facilities did not perform any genetic testing (Fig. 2). Even in the facility where $>100$ clients visited genetic counseling, the number who received implementation of genetic testing was $<50$.

Of all the respondents' facilities, $60.2 \%$ dealt with only $B R C A 1 / 2$ testing and $38.6 \%$ with other targeted genetic testing. 


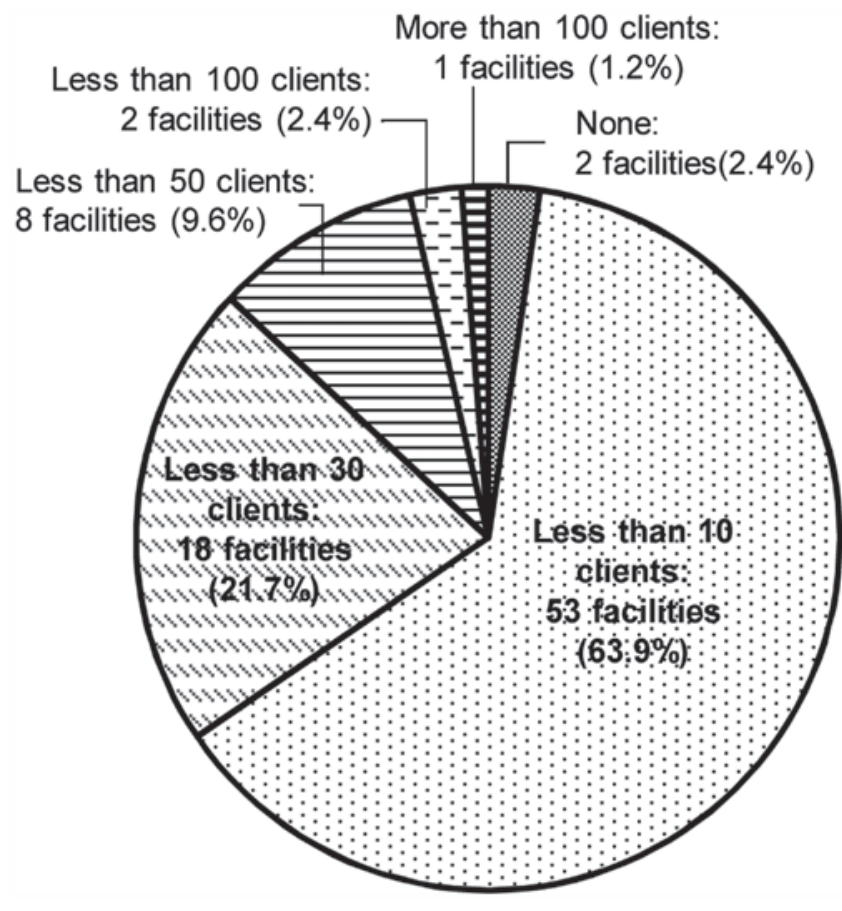

Figure 1. The number of clients who visited genetic counseling regarding hereditary breast cancer in the most recent year.

60

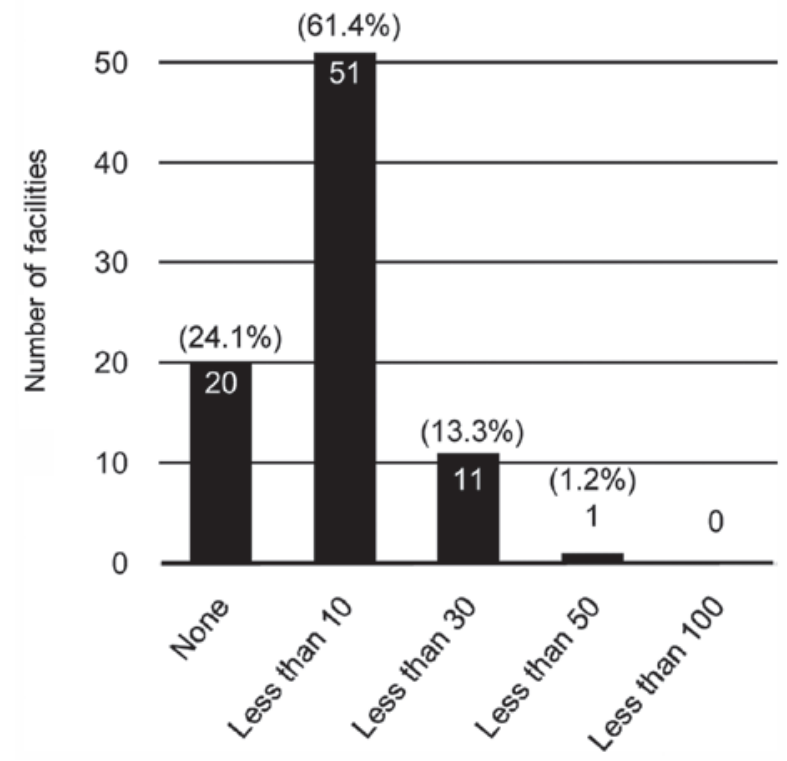

Figure 2. The number of facilities providing genetic testing regarding hereditary breast cancer.

Only four facilities (4.8\%) provided multigene panel testing for HBC.

Status of implementation of RRM and RRSO. RRM was implemented in 19.3\% ( $\mathrm{N}=16)$ of the respondents' facilities and RRSO in $24.1 \%(\mathrm{~N}=20)$ but $\sim 30 \%$ of the facilities that have not implemented RRM and RRSO are currently considering introducing these surgeries (26.9 and $28.6 \%$, respectively) (Table II). In total, $6.0 \%(\mathrm{~N}=5)$ and $18.1 \%(\mathrm{~N}=15)$ of the facilities, respectively, had experience in performing these surgeries and it was therefore identified that RRSO may be more frequently performed than RRM in Japan.

Access to genetic medicine. The respondents were asked about the barriers that impeded visiting genetic counseling, excluding the issues of the high-costs of genetic testing. The majority of the genetic counselors $(\mathrm{N}=7,58.3 \%)$ recognized the need for education of medical staff in order to improve the access to genetic counseling. On the other hand, the clinical geneticists answered that the education of patients with cancer and their families $(\mathrm{N}=14,33.3 \%)$, as well as the education of medical staff $(\mathrm{N}=14)$, was necessary. In addition, respondents thought of the following factors as other barriers to participating in genetic counseling: Negative feelings toward hereditary diseases $(\mathrm{N}=8)$, the lack of human resources such as physician's consultation time regarding HBC $(\mathrm{N}=6)$, and the number of genetic counselors $(\mathrm{N}=5)$ and the clinical and genetic data among Japanese populations $(\mathrm{N}=5)$.

\section{Discussion}

In the past few years, the awareness of HBC in Japan has rapidly grown, partly in reaction to the announcement of a US actress that she underwent a double mastectomy to avoid the risk of breast cancer. Nonetheless, as presented in the current study, $66.3 \%$ of facilities who responded to this survey in Japan answered that the number of clients receiving HBC-associated genetic counseling was $<10$ in the last year, and $24.1 \%$ answered no genetic testing was performed in the past year. As genetic screening for HBC is not covered by public health insurance in Japan, clients taking the test must pay the cost in full ( 200,000 JPY). These financial burdens on patients may be one of the negative factors.

Though the pattern of occurrence of breast and ovarian cancer in a pedigree is characteristic of $\mathrm{HBOC}$, a mutation in the $B R C A 1 / 2$ gene may be identified in more than ninety percent of these pedigrees (21); patients with Li-Fraumeni syndrome, Cowden syndrome and Peutz-Jeghers syndrome have a higher risk of breast cancer (22-24), and $M M R$, CHECK2, PALB2 and ATM gene mutations also increase breast cancer risk (25). Therefore, during the genetic counseling for $\mathrm{HBC}$, a risk assessment to identify the genes including BRCA1/2 that must be examined from the patterns of cancer development in probands and within a family is essential. The current survey revealed that over sixty percent of the facilities provided the BRCA1/2 test alone. As presented in Fig. 3, approximately one half ( $\mathrm{N}=23,47.9 \%)$ of the university hospitals and cancer hospitals offered only $B R C A 1 / 2$ tests for $\mathrm{HBC}$. The services of genetic counseling and genetic testing based on a comprehensive risk assessment of HBC may not be available in these facilities. Although the multi-gene cancer panel test is very useful to analyze the causal genes for HBC, the test has not been widely used in the Japanese clinical setting.

Another issue identified by this survey is a lack of education for health care providers, patients with cancer and their families. In particular, $\sim 60 \%$ of the genetic counselors recognized the needs for education of medical staff. Previous 
Table II. The availability and use of RRM and RRSO.

\begin{tabular}{cccccccc}
\hline & & & & \multicolumn{3}{c}{ Number of uses $(\%)$} \\
\cline { 5 - 8 } & Unavailable, $\mathrm{N}(\%)$ & Under consideration, $\mathrm{N}(\%)$ & Available, $\mathrm{N}(\%)$ & 0 & $<5$ & $<10$ \\
\hline RRM & 67 & 18 & 16 & 11 & 5 & 0 \\
\multirow{3}{*}{ RRSO } & $(80.7)$ & $(26.9)$ & $(19.3)$ & $(68.8)$ & $(31.3 \%)$ & $(-)$ \\
& 63 & 18 & 20 & 5 & 13 & 2 \\
& $(75.9)$ & $(28.6)$ & $(24.1)$ & $(25.0)$ & $(65.0)$ & $(10.0)$ \\
\hline
\end{tabular}

RRM, risk reducing mastectomy; RRSO, risk reducing bilateral salpingo-oophorectomy.

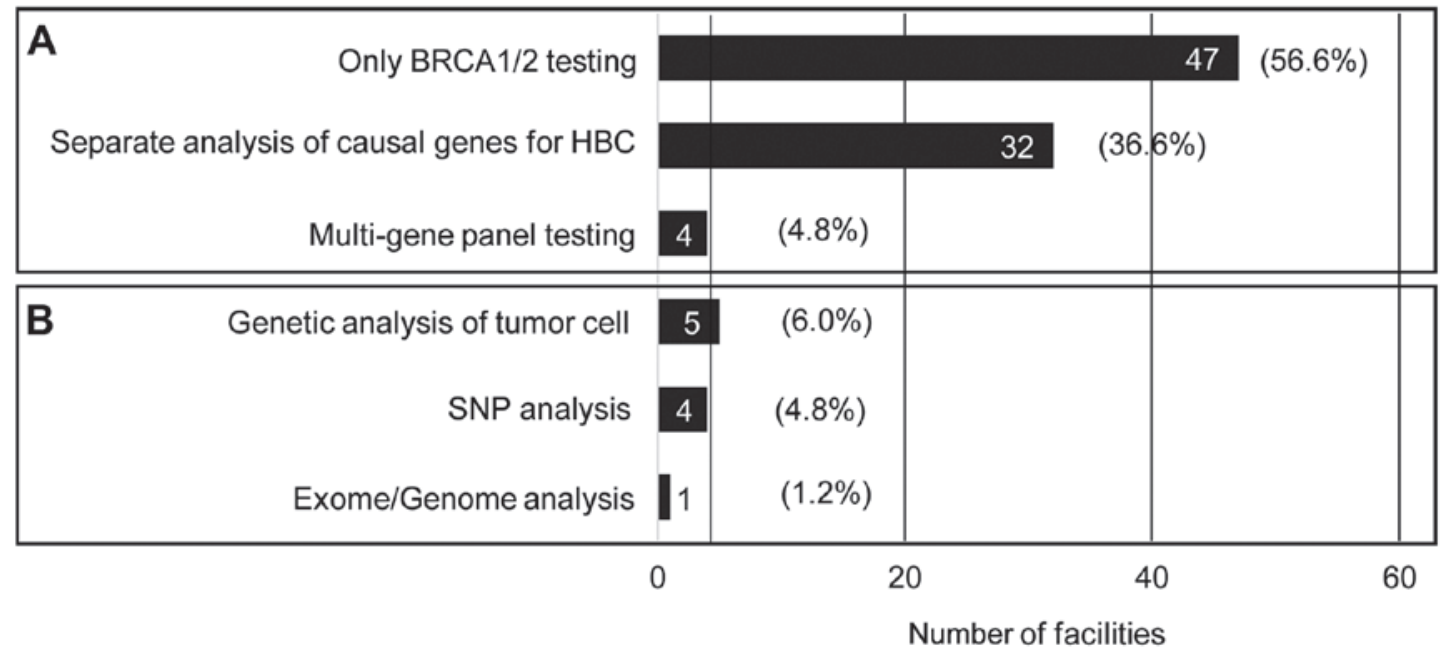

Figure 3. The type of genetic analysis of hereditary breast cancer and breast cancer. Respondents were required to select one item from (A) and to choose applicable items from (B) (multiple answers allowed) if those analyses were available in the respondents' facilities.

studies have revealed that the physicians' recommendation and referral to genetic counseling significantly affected the patients' motivation for receiving genetic counseling (26-28). Particularly in Asia, the physician's referral was a strong motivator (26-28). Accordingly, there is an urgent requirement for the additional education of physicians regarding appropriate referrals for cancer genetics.

Furthermore, certain respondents were concerned about the lack of clinical and genetic data on HBC in Japan. Only 260 individuals with a strong family history of breast cancer at 8 institutions in Japan were recorded and analyzed regarding BRCA1/2 genes by the end of March 2012 (29). The small sample size of this study limits its clinical significance and the results of on-going study are required. Recently, the rate of VUS results among those undergoing the BRCA1/2 genetic testing in the US has decreased $2.1 \%$ from $13 \%$, which was accomplished by numerous efforts directed to the determining the pathogenicity of variants in over one million samples tested over 20 years (18). Therefore, accumulation of data from the Japanese population is essential for effective use of genetic testing.

The overall interpretation of VUS is currently reported in $2.1 \%$ of patients undergoing genetic analysis for HBOC at Myriad Genetic Laboratories $(9,10)$. This represents a decline from around $13 \%$ over the past decade. The dramatic decline in the percentage of patients receiving a VUS result reflects the impact of targeted efforts directed at determining the pathogenicity of variants, as well as the availability of data from an increased number of individuals undergoing testing for HBOC (10).

When a mutation is identified in patients and their unaffected family members, they are provided the option of RRM and RRSO in order to reduce future risk of cancer. However, as presented in Table II, RRM and RRSO are not available in the majority of the facilities in japan. The current study indicates that a comprehensive medical care system is necessary to offer a wider range of options for patients.

In conclusion, the status of genetic medicine for $\mathrm{HBC}$ in Japan has yet to be established. To the best of our knowledge, the present study is the first to examine the frequency of use of genetic testing, RRM and RRSO in Japan. Furthermore, the type of genetic testing was mostly limited to $B R C A 1 / 2$ testing. Clinical practitioners may offer the appropriate testing corresponding to the medical history of patients and their family. The use of the multigene panel testing for HBC may be useful for patients who do not exhibit family history of various cancers other than HBOC. Therefore, the current status of genetic services and the issues regarding $\mathrm{HBC}$ were investigated and it was identified that clinical cancer genetics requires further development in Japan. 


\section{Acknowledgements}

The present study was supported by a grant from the Health Care Science Institute. The authors are grateful to all of the clinical health care providers who participated in the study.

\section{References}

1. Katanoda K, Kamo K, Saika K, Matsuda T, Shibata A, Matsuda A, Nishino Y, Hattori M, Soda M, Ioka A, et al: Short-Term projection of cancer incidence in Japan using an age-period interaction model with spline smoothing. Jpn J Clin Oncol 44: 36-41, 2014.

2. Foulkes WD: Inherited Susceptibility to Common Cancers. N Engl J Med 359: 2143-2153, 2008.

3. Pharoah PD, Antoniou A, Bobrow M, Zimmern RL, Easton DF and Ponder BA: Polygenic susceptibility to breast cancer and implications for prevention. Nat Genet 31: 33-36, 2002.

4. Harkness EF, Barrow E, Newton K, Green K, Clancy T, Lalloo F, Hill $\mathbf{J}$ and Evans DG: Lynch syndrome caused by MLH1 mutations is associated with an increased risk of breast cancer: A cohort study. J Med Genet 52: 553-556, 2015.

5. Risch HA, McLaughlin JR, Cole DE, Rosen B, Bradley L, Fan I, Tang J, Li S, Zhang S, Shaw PA and Narod SA: Population BRCA1 and BRCA2 mutation frequencies and cancer penetrances: A kin-cohort study in Ontario, Canada. J Natl Cancer Inst 98: 1694-1706, 2006.

6. Mavaddat N, Peock S, Frost D, Ellis S, Platte R, Fineberg E, Evans DG, Izatt L, Eeles RA, Adlard J, et al: Cancer risks for BRCA1 and BRCA2 mutation carriers: Results from prospective analysis of EMBRACE. J Natl Cancer Inst 105: 812-822, 2013.

7. Chen S and Parmigiani G: Meta-analysis of BRCA1 and BRCA2 penetrance. J Clin Oncol 25: 1329-1333, 2007.

8. Fostira F, Tsitlaidou M, Papadimitriou C, Pertesi M, Timotheadou E, Stavropoulou AV, Glentis S, Bournakis E, Bobos M, Pectasides D, et al: Prevalence of BRCA1 mutations among 403 women with triple-negative breast cancer: Implications for genetic screening selection criteria: A Hellenic Cooperative Oncology Group Study. Breast Cancer Res Treat 134: 353-362, 2012.

9. Tai YC, Domchek S, Parmigiani G and Chen S: Breast cancer risk among male BRCA1 and BRCA2 mutation carriers. J Natl Cancer Inst 99: 1811-1814, 2007.

10. Gallagher DJ, Gaudet MM, Pal P, Kirchhoff T, Balistreri L, Vora K, Bhatia J, Stadler Z, Fine SW, Reuter V, et al: Germline BRCA mutations denote a clinicopathologic subset of prostate cancer. Clin Cancer Res 16: 2115-2121, 2010.

11. Kirchhoff T, Kauff ND, Mitra N, Nafa K, Huang H, Palmer C, Gulati T, Wadsworth E, Donat S, Robson ME, et al: BRCA Mutations and Risk of Prostate Cancer in Ashkenazi Jews. Clin Cancer Res 10: 2918-2921, 2004.

12. NationalComprehensiveCancer Network: NCCN Clinical Practice Guidelines in Oncology (NCCN Guidelines ${ }^{\circledR}$ ) 'Genetic/Familial High-Risk Assessment: Breast and Ovarian': https://www.nccn.org/professionals/physician_gls/f_guidelines. asp. Accessed November 7, 2016

13. Metcalfe K, Gershman S, Ghadirian P, Lynch HT, Snyder C, Tung N, Kim-Sing C, Eisen A, Foulkes WD, Rosen B, et al: Contralateral mastectomy and survival after breast cance in carriers of BRCA1 and BRCA2 mutations: Retrospective analysis. BMJ 348: g226, 2014.

14. Rebbeck TR, Kauff ND and Domchek SM: Meta-analysis of risk reduction estimates associated with risk-reducing salpingo-oophorectomy in BRCA1 or BRCA 2 mutation carriers. J Natl Cancer Inst 101: 80-87, 2009.

15. Domchek SM, Friebel TM, Neuhausen SL, Wagner T, Evans G, Isaacs C, Garber JE, Daly MB, Eeles R, Matloff E, et al: Mortality after bilateral salpingo-oophorectomy in BRCA1 and BRCA2 mutation carriers: A prospective cohort study. Lancet Oncol 7: 223-229, 2006
16. Yamamoto N, Nokihara H, Yamada Y, Goto Y, Tanioka M, Shibata T, Yamada K, Asahina H, Kawata T, Shi X and Tamura T: A phase I, dose-finding and pharmacokinetic study of olaparib (AZD2281) in Japanese patients with advanced solid tumors. Cancer Sci 103: 504-509, 2012.

17. Lindor NM, Goldgar DE, Tavtigian SV, Plon SE and Couch FJ: BRCA1/2 sequence variants of uncertain significance: A primer for providers to assist in discussions and in medical management. Oncologist 18: 518-524, 2013.

18. Eggington JM, Bowles KR, Moyes K, Manley S, Esterling L, Sizemore S, Rosenthal E, Theisen A, Saam J, Arnell C, et al: A comprehensive laboratory-based program for classification of variants of uncertain significance in hereditary cancer genes. Clin Genet 86: 229-237, 2014

19. Desmond A, Kurian AW, Gabree M, Mills MA, Anderson MJ, Kobayashi Y, Horick N, Yang S, Shannon KM, Tung N, et al: Clinical actionability of multigene panel testing for hereditary breast and ovarian cancer risk assessment. JAMA Oncol 1: 943-951, 2015.

20. Kapoor NS, Curcio LD, Blakemore CA, Bremner AK, McFarland RE, West JG and Banks KC: Multigene panel testing detects equal rates of pathogenic BRCA1/2 mutations and has a higher diagnostic yield compared to limited BRCA1/2 analysis alone in patients at risk for hereditary breast cancer. Ann Surg Oncol 22: 3282-3288, 2015.

21. Ford D, Easton DF, Stratton M, Narod S, Goldgar D, Devilee P, Bishop DT, Weber B, Lenoir G, Chang-Claude J, et al: Genetic heterogeneity and penetrance analysis of the BRCA1 and BRCA2 genes in breast cancer families. The Breast Cancer Linkage Consortium. Am J Hum Genet 62: 676-89, 1998

22. Birch JM, Hartley AL, Tricker KJ, Prosser J, Condie A, Kelsey AM, Harris M, Jones PH, Binchy A, Crowther D, et al: Prevalence and diversity of constitutional mutations in the p53 gene among $21 \mathrm{Li}-F r a u m e n i$ families. Cancer Res 54: 1298-1304, 1994.

23. Pilarski R: Cowden syndrome: A critical review of the clinical literature. J Genet Couns 18: 13-27, 2009.

24. Hearle N, Schumacher V, Menko FH, Olschwang S, Boardman LA, Gille JJ, Keller JJ, Westerman AM, Scott RJ, Lim W, et al: Frequency and spectrum of cancers in the Peutz-Jeghers syndrome. Clin Cancer Res 12: 3209-3215, 2006.

25. Apostolou P and Fostira F: Hereditary breast cancer: The era of new susceptibility genes. Biomed Res Int 2013: 747318, 2013

26. Sussner KM, Jandorf L, Thompson HS and Valdimarsdottir HB Barriers and facilitators to BRCA genetic counseling among at-risk Latinas in New York City. Psychooncology 22: 1594-1604, 2013.

27. Anderson B, McLosky J, Wasilevich E, Lyon-Callo S, Duquette D and Copeland G: Barriers and facilitators for utilization of genetic counseling and risk assessment services in young female breast cancer survivors. J Cancer Epidemiol 2012: 298745, 2012.

28. Chin TM, Tan SH, Lim SE, Iau P, Yong WP, Wong SW and Lee SC: Acceptance, motivators and barriers in attending breast cancer genetic counseling in Asians. Cancer Detect Prev 29: 412-418, 2005.

29. Nakamura S, Takahashi M, Tozaki M, Nakayama T, Nomizu T, Miki Y, Murakami Y, Aoki D, Iwase T, Nishimura S, et al: Prevalence and differentiation of hereditary breast and ovarian cancers in Japan. Breast Cancer 22: 462-468, 2015. 